\title{
LA SOLICITUD DE AUTORIZACIÓN DE RESIDENCIA Y TRABAJO Y NACIONALIDAD PARA DEPORTISTAS PROFESIONALES
}

\author{
Dr. Marc Giménez Bachmann \\ Profesor asociado en la Universidad de Barcelona \\ Email: mgimenezbachmann@gmail.com
}

Dra. Carmen Parra Rodríguez

Profesora de Derecho Internacional Privado

en la Universidad Abat Oliba- CEU

Email: cparra@uao.es

RESUMEN: España es un país con gran tradición deportiva, que posee clubs deportivos centenarios en deportes como el fútbol, el baloncesto, el ciclismo, el tenis y el balonmano.

Muchos deportistas profesionales desean u obtienen ofertas para pertenecer a equipos de clubs deportivos españoles, para lo cual deben obtener de manera previa una autorización de residencia y trabajo para poder incorporarse laboralmente a los mismos.

De la misma manera, con posterioridad a muchos clubs deportivos les interesa que estos deportistas de élite extranjeros soliciten la nacionalidad española, para ser contabilizados como jugadores españoles o comunitarios y no extra comunitarios cuyo número se encuentra limitado.

PALABRAS CLAVE: Deportista- autorización de residencia y trabajo- nacionalidad española.

RESUM: Espanya és un país amb una gran tradició esportiva, que compta amb clubs esportius centenaris en esports com el futbol, el bàsquet, el ciclisme y el handbol. 
Molts esportistes professionals desitgen o obtenen ofertes per tal de passar a pertànyer a equips d'un club esportiu espanyol, per a la qual cosa han d'obtenir prèviament una autorització de residencia i treball amb l'objectiu de poder incorporar-s'hi laboralment.

Igualment, amb posterioritat a aquesta incorporació, a molts clubs esportius els interessa que aquests esportistes professionals demanin i obtinguin la nacionalitat espanyola, per tal de que puguin esser comptabilitzats com a esportistes espanyols o comunitaris i no ja com a extra comunitaris, el número dels quals es troba limitat.

PARAULES CLAU: Esportista- autorització de residencia i treball- nacionalitat espanyola.

ABSTRACT: Spain is a country with a high sport tradition which has centenary sports clubs in different sports like football, basketball, cycling, tennis and handball.

Many professional athletes whish or get offers in order to belong for teams of different Spanish sports clubs, for this they must obtain beforehand a residence and work permit to be able to join them.

As the same way, many of these sport clubs are interested that these foreign elite athletes applying for Spanish nationality, to be counted as Spanish players or community and not extra community, whose number is limited.

KEYWORDS: Athlete - residence and work permit - Spanish nationality.

Sumario: Resumen/Resum/Abstract. Introducción. Diferentes posibilidades para regularizar a deportistas en España. 1. Residencia y trabajo para extranjeros deportistas provenientes de la UE. 2. Residencia y trabajo para deportistas extranjeros no pertenecientes a un Estado de la UE. 2.1. Autorización de residencia y trabajo inicial para deportistas profesionales. 2.1.1. Fase a realizar por el empresario desde España. 2.1.2. Fase a realizar por el extranjero desde su país de origen o residencia legal. 2.2. Autorización de residencia temporal y trabajo por cuenta ajena de duración determinada. 2.3. Autorización de residencia por circunstancias excepcionales. 2.4. Residencia por la ley de emprendedores 14/2013. 3. Especial referencia al cupo de deportistas no comunitarios permitido. 4. Jurisprudencia de la Unión europea sobre cupos de deportistas extranjeros. 5. Nacionalidad española para deportistas extranjeros. 5.1. Nacionalidad española por opción. 5.2. Nacionalidad española por carta de naturaleza. Conclusiones. Bibliografía.

\section{INTRODUCCIÓN}

En el siglo XXI en el que vivimos, nos encontramos en un mundo totalmente globalizado, donde los flujos migratorios y el traslado de ciudadanos para trabajar en un país que no es el suyo son cada vez más frecuentes. 
La realidad jurídica del Derecho de Extranjería para poder regularizar a ciudadanos extranjeros en España, es compleja y llena de requisitos que deben cumplirse; no es lo mismo regularizar a un ciudadano extranjero miembro de un país de la Unión Europea que a uno que no pertenece a uno de dichos Estados Miembros o regularizar a un ciudadano extranjero de un tercer Estado que se encuentra en su país de origen o a otro que se encuentra de manera irregular en España.

Es por este motivo, que aunque dichos traslados de personas se produzcan de manera tan numerosa, hay casos en los que, a pesar de la gran necesidad de una empresa contratante de poder contar con un determinado trabajador extranjero, existe una gran dificultad legal en el trámite a realizar, para que dicho traslado sea legalmente posible, si el ciudadano extranjero se encuentra en su país de origen y aún más si éste se encuentra de manera irregular en España.

En el caso de los deportistas, esto no constituye ninguna excepción, ya que cuando un club deportivo encuentra por ejemplo a un jugador de fútbol que desea incluir en su plantilla, no siempre el dinero lo hace del todo posible, ya que deben superarse los trámites que impone la normativa para que dicha contratación llegue a buen fin. Veremos que únicamente el procedimiento es algo menos complicado, en el caso de deportistas de élite, aunque tal calificación está muy limitada. En el caso de los deportistas profesionales extranjeros, éstos además de estar sujetos las normas laborales y a las que impone la ley de extranjería, estarán sometidos a las restricciones que imponen las normas federativas con respecto al número máximo de extranjeros que pueden formar parte del equipo y participar en encuentros ${ }^{1}$.

Igualmente, al llevar el análisis, hay que tener claro que habrá que diferenciar los supuestos que rigen para ciudadanos extranjeros, según sean éstos pertenecientes a un Estado miembro de la Unión Europea ${ }^{2}$ (en adelante UE) o del Espacio Económico Europeo $^{3}$ (en adelante EEE) y Suiza ${ }^{4}$ o no. También se debe determinar qué son y que entiende la ley de Extranjería por un deportista profesional, para diferenciarlos de otros

\footnotetext{
${ }^{1}$ Bosch Capdevila, E y Franquet Sugrañes, M.T. (Coords): Dopaje, fraude y abuso en el deporte. Ed. Bosch.2007. Barcelona. Pág. 235.

2 Alemania, Austria, Bélgica, Bulgaria, Chipre, Croacia, Dinamarca, Eslovaquia, Eslovenia, España, Estonia, Finlandia, Francia, Grecia, Hungría, Irlanda, Italia, Letonia, Lituania, Luxemburgo, Malta, Países Bajos, Polonia, Portugal, Reino Unido, R. Checa, Rumanía y Suecia.

${ }^{3}$ Islandia, Liechtenstein y Noruega.

${ }^{4}$ Por acuerdo de 21 de junio de 1999, entre la Comunidad se les aplica el Régimen Comunitario. DOUE núm. 114, de 30 de abril de 2002.
} 
en que el ciudadano extranjero únicamente tiene la calificación de deportista; la norma establece cuáles son los supuestos en los que se le considera como profesional, y que se encuentran limitados a unos casos concretos enumerados.

Si bien en los supuestos más usuales, requieren en solicitudes iniciales que el ciudadano extranjero no se encuentre en España de manera irregular (claro está que podríamos llegar a ellas por una modificación de una autorización previa), existe un tipo de autorización de residencia, que se podría solicitar estando el ciudadano extranjero en España, siempre que no sea de manera irregular, por ejemplo durante la vigencia de su visado de turista, por aplicación de la Ley de Emprendedores ${ }^{5}$.

Por último, como posibilidad para regularizar a un deportista profesional con una autorización de residencia y trabajo haré referencia a la posibilidad, quizá remota o quizá no tanto, de que los ciudadanos extranjeros que se encuentran de manera irregular en España, podrían regularizar también su situación como deportistas, o deportistas profesionales, si cumplen con los requisitos que imponen la Ley de extranjería y su Reglamento $^{6}$, para los supuestos de arraigo social, ya que tras el estudio de la norma no veo inconveniente para ello (a pesar de que tras la consulta a las Administraciones éstas no se han posicionado al respecto).

Por otro lado, en el caso de deportistas calificados como profesionales, encontraremos los requisitos que se imponen a los clubs deportivos, a cerca de la posibilidad de contar con un número u otro de ciudadanos españoles o miembros de la UE y los que no lo sean. Al existir unos cupos de ciudadanos extracomunitarios que no se pueden superar por parte de un club deportivo, es importante que dichos deportistas puedan obtener la nacionalidad española.

Así, haremos mención de las dos vías por las que dichos deportistas profesionales podrán adquirir la nacionalidad española.

\footnotetext{
${ }^{5}$ Ley 14/2013, de 27 de septiembre, de apoyo a los emprendedores y su internacionalización (BOE núm. 233, de 28 de septiembre de 2013).

${ }^{6}$ Artículos 31.1, 3 y 4 de la Ley Orgánica 4/2000 (Ley Orgánica 4/2000, de 11 de enero, sobre Derechos y Libertades de los Extranjeros en España y su Integración Social. BOE núm. 10, de 12 de enero de 2000) y 45.2.b) de su Reglamento (Real Decreto 557/2011, de 20 de abril por el que se aprueba el Reglamento de la Ley Orgánica 4/2000, sobre derechos y libertades de los extranjeros en España y su integración social, tras su reforma por Ley Orgánica 2/2009. BOE núm. 103, de 30/04/2011).
} 
DIFERENTES POSIBILIDADES PARA REGULARIZAR A DEPORTISTAS

\section{EN ESPAÑA}

Dentro de las diferentes posibilidades que se van a analizar, se van a tener en cuenta los supuestos en los cuales un ciudadano extranjero proviene de un Estado Miembro de la Unión Europea o no, y los supuestos en los cuáles el ciudadano extranjero se encuentra en su país de origen o de residencia legal o de manera irregular en España.

\section{Residencia y trabajo para extranjeros deportistas provenientes de la UE}

Éste es el supuesto más sencillo, ya que a los ciudadanos extranjeros que pertenezcan a uno de estos Estados, les será de aplicación la normativa prevista en el Real Decreto 240/2007, sobre entrada, libre circulación y residencia en España de ciudadanos de los Estados Miembros de la Unión Europea y de otros Estados parte en el Acuerdo sobre el Espacio Económico Europeo ${ }^{7}$ (en adelante RD 240/2007), que permite la libre circulación y la residencia de los ciudadanos extranjeros por todo el territorio de la Unión.

Estos ciudadanos, si tienen intención de residir en España, únicamente deberán notificarlo a la Dirección General de Policía, solicitando su inscripción en el Registro Central de Extranjeros la cual les asignará junto a esta inscripción un número de identificación de extranjeros (en adelante NIE). Para realizar este acto, deberán presentar su documentación identificativa, acreditar con qué medios de vida cuentan (o en el caso de que vayan a realizar una actividad laboral en España, sea por cuenta propia o ajena, acreditar la que será), así como acreditar que cuentan con un seguro médico público o privado ${ }^{8}$.

\footnotetext{
${ }^{7}$ Real Decreto 240/2007, de 16 de febrero, sobre entrada, libre circulación y residencia en España de ciudadanos de los Estados Miembros de la Unión Europea y de otros Estados parte en el Acuerdo sobre el Espacio Económico Europeo. (BOE núm. 51, de 28 de febrero de 2007).

${ }^{8}$ Este requisito se introdujo para los ciudadanos extranjeros que no vayan a realizar una actividad laboral en España y que no estarán afiliados por tanto a la Seguridad Social, tras la entrada en vigor del Real Decreto-ley 16/2012, de 20 de abril, de medidas urgentes para garantizar la sostenibilidad del Sistema Nacional de Salud y mejorar la calidad y seguridad de sus prestaciones. (BOE núm. 98, de 24 de abril de 2012).
} 
Una vez que el ciudadano extranjero, posea este certificado de inscripción, podrá residir de manera indefinida en España y realizar la actividad por cuenta propia o ajena que desee.

\section{Residencia y trabajo para deportistas extranjeros no pertenecientes a un Estado}

\section{de la UE}

Para estos ciudadanos extranjeros nos encontramos con diferentes posibilidades, según nos refiramos a deportistas que se encuentren o no en España de manera irregular, profesionales que tengan tal consideración por encontrarse encuadrados en el listado que se encuentra aprobado por el Acuerdo del Consejo de Ministros de 15 de julio de $2005^{9}$ y desarrollado en la Instrucción DGI/SGRJ/02/2009 ${ }^{10}$ y los deportistas que carezcan de tal consideración.

A éstos últimos deberemos solicitarles la autorización de residencia y trabajo prevista para los profesionales altamente cualificados artistas y deportistas, solicitándoles una autorización de residencia temporal y trabajo por cuenta ajena de duración determinada para deportistas ${ }^{11}$. Encontramos un supuesto también en la legislación mexicana, en la que un ciudadano extranjero que se encuentre de manera irregular en su territorio nacional, podrá solicitar una autorización de residencia y trabajo, en el caso de que la actividad que va a desempeñar sea la de cargo de confianza, científico, técnico, familiares, artistas o deportistas ${ }^{12}$.

\footnotetext{
${ }^{9}$ RESOLUCIÓN de 19 de julio de 2005, de la Secretaría General para la Administración Pública, por la que se dispone la publicación del Acuerdo del Consejo de Ministros de 15 de julio de 2005, para la implantación de una Red de Oficinas Integradas de Atención al Ciudadano en colaboración con las Comunidades Autónomas y las Entidades que integran la Administración Local (BOE núm. 184, de 3 de agosto de 2005.

10 INSTRUCCIÓN DGI/SGRJ/02/2009, sobre el acuerdo de Consejo de Ministros, de 15 de julio de 2006, por el que se aprueban las instrucciones por las que se determina el procedimiento para autorizar la residencia y el desarrollo de actividades laborales deportivas profesionales por extranjeros. http://extranjeros.empleo.gob.es/es/normativa/nacional/general_extranjeria/instrucciones_sgie/documento s/2009/INSTRUCCION DGI-SGRJ-02-2009.pdf (fecha de consulta 22.10.2015).

${ }^{11}$ Artículo 98.2.c. del RD 557/2011.

12 Acuerdo que tiene por objeto establecer los criterios conforme a los cuales, los extranjeros de cualquier nacionalidad que se encuentren de manera irregular en territorio nacional y manifiesten su interés de residir en el mismo, puedan promover la obtención de su documentación migratoria en la calidad de inmigrante con las características de profesional, cargo de confianza, científico, técnico, familiares, artistas o deportistas o bien, en la característica de asimilado en los casos que de manera excepcional se establecen en el presente. Diario Oficial de la Federación (primera sección) de martes de 11 de noviembre de 2008.
} 
Si bien en ambos casos anteriores el ciudadano extranjero debe encontrarse en su país de origen, en tercer lugar existe el procedimiento de solicitud de autorización de residencia por circunstancias excepcionales, en el que el ciudadano extranjero se puede encontrar en España y por último el procedimiento para profesionales altamente cualificados incluidos en la Ley de emprendedores.

\subsection{Autorización de residencia y trabajo inicial para deportistas profesionales}

Este supuesto es el que prevé la Ley de Extranjería, para los casos en los que se desee contratar a un ciudadano extranjero, en este caso deportista profesional, siguiendo el procedimiento para solicitar una autorización de residencia temporal y trabajo por cuenta ajena inicial. Este procedimiento sería por tanto aquel, por el cual un club deportivo radicado en España desea contratar a un deportista profesional que se encuentra en su país de origen o en el de su residencia legal.

Para ello, la empresa contratante deberá realizar la presentación de una solicitud en la oficina de extranjeros correspondiente (o si cumple con los requisitos de ser gran empresa al contar con más de 250 trabajadores, en la Unidad de Grandes Empresas de Madrid, en adelante UGE), tal y como fija el Estatuto de los Trabajadores $^{13}$ en su artículo 7.c), al hablar de la capacidad para contratar, que establece que "podrán contratar la prestación de su trabajo: c) Los extranjeros, de acuerdo con lo dispuesto en la legislación específica sobre la materia”.

Es por este motivo entonces, por el cual debemos poner en relación tres normas:

- $\quad$ La LO 4/2000, de 11 de enero sobre derechos y libertades de los extranjeros en España y su integración social (en adelante LO 4/2000) ${ }^{14}$.

- Real Decreto 557/2011, de 20 de abril, por el que se aprueba el Reglamento de la Ley Orgánica 4/2000, sobre derechos y libertades de los extranjeros en España y su integración social, tras su reforma por Ley Orgánica 2/2009 (en adelante RD 557/2011) ${ }^{15}$ y que desarrolla la norma anterior.

\footnotetext{
${ }^{13}$ Real Decreto Legislativo 1/1995, de 24 de marzo, por el que se aprueba el texto refundido de la Ley del Estatuto de los Trabajadores (BOE núm. 75, de 29 de marzo de 1995).

${ }^{14}$ BOE núm. 10, de 12 de enero de 2000.

${ }^{15}$ BOE núm. 103, de 30 de abril de 2011.
} 
Hasta aquí, la normativa que se aplica a toda solicitud de autorización de residencia y trabajo para cualquier ciudadano extranjero que desee residir de manera regular en España.

En el caso de deportistas, debemos contemplar además dos regulaciones más:

- El Real Decreto 1006/1985 por el que se regula la relación laboral especial de los deportistas profesionales ${ }^{16}$ (en adelante RD 1006/1985) a la que se refiere el artículo 2.1.d) del ET. El ET en cuestiones de deportistas extranjeros dice en su artículo 2, al hablar de la capacidad para contratar por razón de nacionalidad, que en materia de nacionalidad, se estará a lo que disponga la legislación vigente para los trabajadores extranjeros en España.

- Para este caso de los deportistas profesionales se aplica el acuerdo del Consejo de Ministros de 15 de julio de $2005^{17}$ por el que se aprueban las instrucciones por las que se determina el procedimiento para autorizar la residencia y el desarrollo de las actividades laborales deportivas profesionales por extranjeros cuyo procedimiento se ha desarrollado por la instrucción DGI/SGRJ/02/2009 ${ }^{18}$.

Vemos por tanto que si bien debemos cumplir con lo que establece el ET, sin perjuicio de la aplicación de las normas específicas que pudieran existir sobre participación en competiciones oficiales y las especialidades referidas a la extinción del contrato de trabajo por el paso del tiempo convenido, tanto éste como el RD 1006/1985, nos remiten a la legislación de extranjería en el momento en el que existe un punto de conexión extranjero.

La LO 4/2000 regula en sus artículos 36, 38 y 40 los aspectos que deben tenerse en cuenta en el caso de que se desee solicitar la autorización de residencia temporal y trabajo por cuenta ajena. Se incluyen tanto los requisitos que deben cumplir para

\footnotetext{
${ }^{16}$ BOE núm. 153, de 27 de junio de 1985.

17 Recogido en la Resolución de 12 de agosto de 2005, de la Secretaría de Estado de inmigración y Emigración, por la que se dispone la del Acuerdo de Consejo de Ministros, de 15 de julio de 2005, por el que se aprueban las instrucciones por las que se determina el procedimiento para autorizar la residencia y el desarrollo de actividades laborales deportivas profesionales por extranjeros (BOE núm. 200, de 22 de agosto de 2005).

${ }^{18}$ Instrucción DGI/SGRJ/02/2009, sobre el acuerdo del Consejo de Ministros, de 15 de julio de 2005, por el que se aprueban las instrucciones por las que se determina el procedimiento para autorizar la residencia y el desarrollo de actividades laborales deportivas profesionales por extranjeros.
} 
solicitar la autorización la empresa contratante como el ciudadano extranjero, así como en el artículo 40 la enumeración de los casos en los cuales la solicitud que desea realizar la empresa contratante, no se encuentra sometida a la situación nacional de empleo.

En primer lugar hay que tener en cuenta que los ciudadanos extranjeros mayores de dieciséis años ${ }^{19}$ necesitarán para poder desempeñar cualquier actividad laboral en España, estar en posesión de la correspondiente autorización administrativa para residir y trabajar $\mathrm{y}$, salvo en el caso que se determinen reglamentariamente, ambas autorizaciones se concederán a la vez. También es requisito legal, que el ciudadano extranjero carezca de antecedentes penales en España y en su país de origen, por delitos tipificados en el ordenamiento jurídico español.

Igualmente, en el caso de que para la actividad que se propone realizar el ciudadano extranjero se requiera una titulación especial, la concesión de la autorización solicitada estará condicionada a la tenencia de la misma, así como a la homologación del título en el caso de que éste fuera necesario.

Entrando en aspectos prácticos para la tramitación real, el procedimiento a seguir será en dos fases:

\subsubsection{Fase a realizar por el empresario desde España}

La primera se realizará por el empresario en España, y consistirá en la solicitud de la autorización de residencia temporal y trabajo correspondiente, en la Oficina de extranjeros del lugar en el que se va a llevar a cabo la actividad laboral ${ }^{20}$.

La documentación que deberá presentarse será:

\footnotetext{
${ }^{19}$ Ya que entre 16 y 18 años podrán ejercer una actividad lucrativa en España con autorización de sus progenitores o de sus tutores (artículo 6 del ET).

${ }^{20}$ Hay que tener en cuenta, a efectos de órgano competente que si bien es susceptible de que se transfiera a otras Comunidades Autónomas, en Cataluña esta competencia ha sido transferida a la Generalitat de Catalunya Cataluña es de momento la única Comunidad Autónoma que ha asumido las competencias en materia de extranjería. El artículo 138.2 del Estatuto de Autonomía de Cataluña, reformado por la Ley Orgánica 6/2006, de 19 de julio (BOE núm. 172 de 20 de Julio de 2006), establece que corresponde a la Generalitat la competencia ejecutiva en materia de autorización de trabajo de los extranjeros cuya relación laboral se desarrolle en Cataluña. Fruto de este artículo es el Real Decreto 1463/2009, de 18 de septiembre, sobre traspaso de funciones y servicios a la Generalitat de Cataluña en materia de inmigración: autorizaciones iniciales de trabajo por cuenta propia o ajena de los extranjeros cuya relación laboral se desarrolle en Cataluña (BOE núm. 229, de 22 de septiembre de 2009).
} 


\begin{tabular}{|l|l|}
\hline Documentos necesarios & Particularidades \\
\hline Pasaporte & fotocopia completa \\
\hline Tasa de residencia & $10,61 €$ (en 2017) \\
\hline Tasa de trabajo & $\begin{array}{l}\text { si salario superior a 20.000€, 450€ } \\
\text { (aproximadamente en 2017) }\end{array}$ \\
\hline Contrato de trabajo & firmado por ambos \\
\hline DNI empresario & solo para persona jurídica \\
\hline CIF & solo para persona jurídica \\
\hline Escritura de poder & si es exigible para la actividad \\
\hline titulación académica & si no son aplicables excepciones \\
\hline $\begin{array}{l}\text { Gestión ante el servicio público } \\
\text { de empleo }\end{array}$ & por parte del empresario contratante \\
\hline Medios económicos suficientes & $\begin{array}{l}\text { que el club sea uno de los del listado de los } \\
\text { del Acuerdo de Ministros de } 15 \text { de julio de } \\
\text { 2005 }\end{array}$ \\
\hline $\begin{array}{l}\text { En caso de deportistas } \\
\text { profesionales }\end{array}$ & del deportista profesional \\
\hline Licencia deportiva & \\
\hline
\end{tabular}

Si analizamos uno por uno los documentos a aportar para ver sus diferentes particularidades:

- en primer lugar la fotocopia completa del pasaporte del ciudadano extranjero, para comprobar que el ciudadano extranjero no se encuentra de manera irregular en España en el momento de la solicitud ${ }^{21}$

- las tasas de residencia y trabajo ya que el hecho imponible es la solicitud de la autorización

- el contrato de trabajo firmado por el propio extranjero y por el empresario, o aquella persona que ostente la representación legal de la empresa y esté facultado para ello, cuya duración no sea inferior a un año y cuyas condiciones se ajusten a las establecidas en la normativa laboral vigente para la misma actividad, categoría profesional y localidad

\footnotetext{
${ }^{21}$ Artículo 64.2.a) del RD 557/2011.
} 
- la identificación del empresario con copia de su DNI, y en el caso de que éste sea persona jurídica, documento público debidamente inscrito a favor de quién firma tanto la solicitud como el contrato de trabajo.

- La acreditación de la titulación exigida académica y/o profesional, la cual deberá estar homologada, si la titulación es exigible para la realización de la actividad, ya que sino simplemente bastará con que esté legalizada y traducida. Igualmente deberá aportarse certificado de inscripción al colegio profesional y en el caso de que no se pueda aportar por requerirse previamente la autorización de residencia y trabajo, bastará el documento de solicitud de inscripción.

- Deberá realizarse la gestión ante los servicios públicos de empleo, con el fin de acreditar la imposibilidad de cubrir el puesto de trabajo ofertado con personas nacionales o extranjeras residentes legales. Este requisito no debe cumplirse en el caso de que la actividad se encuentre incluida en el catálogo de ocupaciones de difícil cobertura que publica trimestralmente el Servicio Público de Empleo Estatal (en adelante SEPE) ${ }^{22}$.

Si bien la actividad lleva actualmente tiempo incluida, hay que tener en cuenta también, para el caso de que algún día suprimieran la profesión de deportista profesional y entrenador deportivo del catálogo de ocupaciones de difícil cobertura, que habría que realizar la gestión que acabo de nombrar. Otra excepción a la obligación de tener que realizar la gestión ante los servicios públicos de empleo la encontramos cuando el ciudadano extranjero cumple con alguno de los supuestos recogidos en el artículo 40 a LO $4 / 2000^{23}$.

- El empleador deberá acreditar que cuenta con los medios económicos suficientes para hacer frente a las obligaciones dimanantes del contrato de trabajo realizados y que no posee deudas ni en Hacienda ni en la Seguridad Social, lo cual podrá acreditar mediante los correspondientes certificados de encontrarse al corriente de sus obligaciones con ambos organismos, y si no los aporta, la Administración lo comprobará de oficio. Si el empresario es

\footnotetext{
${ }^{22}$ En dicho listado, en momentos actuales se incluyen únicamente veinte actividades de las cien que había llegado a tener, pero dentro de las mismas se encuentran la de deportista profesional y entrenadores deportivos.

23 Dicho artículo hace una enumeración de supuestos en los cuales no se tendrá en cuenta la situación nacional de empleo e incluye en el apartado segundo, unos supuestos que se desarrollarán reglamentariamente entre los que se encuentra el profesional altamente cualificado.
} 
persona física, aportará su declaración de la renta del último ejercicio fiscal y si es para empresas con menos de diez trabajadores, deberá aportar las cuatro últimas declaraciones de IVA presentadas y en el caso de sociedades cooperativas el libro de registro de los socios.

- Solamente para el caso de deportistas profesionales y entrenadores hay que tener en cuenta lo que establecen el Acuerdo del Consejo de Ministros de 15 de julio de 2005 y la Instrucción DGI/SGRJ/02/2009,que establece que podrán realizar solicitudes de autorizaciones de residencia y trabajo para deportistas profesionales, en calidad de empleadores y empleadoras, los clubes deportivos, asociaciones deportivas, sociedades anónimas deportivas o el resto de entidades inscritas en las competiciones que a continuación enumeraré y que deseen contratar por un plazo máximo de un año no renovable, en calidad de entrenador y deportistas profesionales, a personas extranjeras que estén en posesión de una licencia deportiva que les habilite para participar en competiciones deportivas oficiales.

Los supuestos en los que se puede seguir este trámite es:

- Baloncesto:

- $\quad$ Liga ACB (Asociación de Clubes de Baloncesto Masculinos)

- $\quad$ Liga LEB (Liga Española de Baloncesto Masculino)

- Liga Femenina de Baloncesto

- Balonmano:

- División de Honor "A" Masculina (Liga ASOBAL)

- División de Honor Femenina

- Ciclismo:

- Clubes o equipos incluidos en el UCI PRO TOUR

- Fútbol:

- $\quad$ Liga Nacional de Fútbol Profesional (1 a y 2 a División de Fútbol Masculino) 
- Primera División de Fútbol Femenino

- División de Honor de la Liga de Fútbol Sala masculino

- División de honor de la Liga de Fútbol Sala femenino

- Voleibol:

- División de Honor Masculina

- División de Honor Femenina

En los casos en los que esto se dé, deberá aportarse una certificación expedida por la correspondiente federación deportiva, liga profesional o entidad asimilada y visada por el Consejo Superior de Deportes, en la que se haga constar:

- El reconocimiento de la empresa solicitante como entidad deportiva inscrita y autorizada para participar en las actividades y competiciones deportivas establecidas i/o, si procede, la capacidad de la entidad deportiva para poder contratar como deportista profesional, en aplicación de las normas específicas sobre participación en competiciones deportivas, a la persona objeto de la solicitud.

- Que el deportista se encuentre en posesión de una licencia que le habilite para el ejercicio de la actividad deportiva.

Este procedimiento autoriza con carácter provisional el inicio de la relación laboral con anterioridad a la resolución de la solicitud, siempre y cuando se realicen los trámites previstos en el Acuerdo citado y se proceda con carácter previo al cumplimiento de las obligaciones empresariales en materia de Seguridad.

Una vez solicitada la autorización de residencia y trabajo por cuenta ajena inicial la administración deberá emitir una resolución en el plazo de tres meses ${ }^{24}$, concediendo la autorización de residencia y trabajo inicial, la cual quedará en suspenso hasta que el ciudadano extranjero obtenga el visado en la Misión Diplomática y el empresario contratante le dé de alta en el régimen de la seguridad social en el plazo de tres meses desde su entrada legal en España.

\footnotetext{
${ }^{24}$ Artículo 67.6 del RD 557/2001.
} 
2.1.2. Fase a realizar por el extranjero desde su país de origen o residencia legal

La segunda fase la realizará el ciudadano extranjero desde su país de origen o desde aquél en el que se encuentre residiendo de manera regular, acudiendo a la embajada o consulado de España para solicitar el visado mediante la presentación de la concesión que se ha emitido en España y que el empresario contratante le habrá remitido.

\subsection{Autorización de residencia temporal y trabajo por cuenta ajena de duración determinada}

Este supuesto se encuentra recogido en el artículo 98 del RD 557/2011 y es un procedimiento previsto para personal de alta dirección, para deportistas y para artistas.

La autorización de residencia temporal y trabajo por cuenta ajena de duración determinada se tramitará según lo que se establece para el procedimiento y requisitos de las autorizaciones de residencia y trabajo por cuenta ajena iniciales, a la que nos hemos referido en el apartado anterior, pero este tipo de autorizaciones posee una especialidad con respecto a la anterior.

La diferencia que tiene este tipo de autorizaciones es con respecto a su duración; la autorización se concederá por el plazo de duración del contrato de trabajo que se aporte en la solicitud de la autorización, y en el caso de que no se establezca una vigencia en el mismo, con la duración de la actividad debidamente acreditada. Con carácter general, la duración total de la autorización no podrá exceder de los doce meses, tras los cuales no será susceptible de prórroga, excepto en el supuesto excepcional de que existan circunstancias sobrevenidas, debidamente acreditadas por el empleador, que hagan necesaria la continuidad de la relación laboral siempre que la normativa laboral lo permita.

Una vez finalizada la relación laboral, el ciudadano extranjero deberá regresar a su país de origen y presentarse ante la misión diplomática u oficina consular que le expidió el visado en el plazo de un mes desde la finalización de su autorización de residencia en España. El incumplimiento de esta obligación, podrá ser causa para la denegación de posteriores solicitudes de autorización para trabajar que pueda realizar el ciudadano extranjero en los siguientes tres años. 


\subsection{Autorización de residencia por circunstancias excepcionales}

Aunque la administración no se posiciona al respecto, existe otro procedimiento para regularizar a extranjeros que se encuentran de manera irregularmente en España en el momento de la solicitud que es la autorización de residencia por circunstancias excepcionales, concretamente el arraigo social.

Si bien puede ser más o menos fácil encontrarse ante este supuesto recogido en el artículo 31.3 de la LO 4/2000 y en los artículos del 62 al 66 y del 123 al 130 del RD $557 / 2011$

Este procedimiento se entiende que se puede dar para los ciudadanos extranjeros que se encuentran de manera irregular en España durante tres años, y que poseen un contrato de trabajo y que podrán por tanto solicitar una autorización de residencia por circunstancias excepcionales con la posibilidad de trabajar en este caso por cuenta ajena.

Como que ni la ley ni el reglamento al hablar de los requisitos que debe tener el contrato de trabajo rehúsan la posibilidad de que éste pueda ir encaminado a una u otra actividad, entiendo que sería totalmente aceptable para el caso de los deportistas profesionales.

Los requisitos que deberá cumplir el contrato de trabajo es que deberá ser al menos por un año, y por un salario superior al Salario Mínimo Interprofesional, la cual cosa en el caso de un deportista profesional sería fácil de cumplir.

Igualmente, en el caso de no contar con vínculos de parentesco con ciudadanos extranjeros residentes en España (ascendientes, descendientes o cónyuge) deberá solicitar un informe de inserción social en la corporación local del lugar de su domicilio.

El ciudadano extranjero que pretenda regularizar su situación obtendrá una autorización de residencia por circunstancias excepcionales, cuya duración será de un año renovable, en el caso de que al finalizar la misma cumpla con las condiciones para ello.

\subsection{Residencia por la ley de emprendedores 14/2013}

Desde la promulgación de la Ley 14/2013 de apoyo a los emprendedores y su internacionalización, que tiene por objeto el promover la inversión y el talento en 
España $^{25}$, existen cinco nuevos tipos de autorizaciones de residencia y trabajo que se regulan por esta norma, y a las que les es de aplicación la LO 4/2000 de manera supletoria. Dentro de los cinco nuevos tipos de visados y autorizaciones de residencia ${ }^{26}$ podríamos encuadrar a los deportistas de élite, los cuales podrían solicitar una autorización de residencia y trabajo como profesionales altamente cualificados siempre que la empresa contratante cumpla con los requisitos legalmente exigidos en este supuesto $^{27}$.

Los requisitos, de entre los cuales la empresa o grupo de empresas contratante deberá cumplir al menos uno, son que ${ }^{28}$ :

- Que el promedio de plantilla durante los tres meses inmediatamente anteriores a la presentación de la solicitud sea superior a 250 trabajadores en España, en alta en el correspondiente régimen de la Seguridad Social.

- Que el volumen de cifra neta anual de negocios de la empresa sea superior, en España, a 50 millones de euros; o que el volumen de fondos propios o patrimonio neto sea superior, en España, a 43 millones de euros.

- Que la inversión bruta media anual, procedente del exterior, no sea inferior a 1 millón de euros en los tres años inmediatamente anteriores a la presentación de la solicitud.

- Que se trate de una empresa con un valor del stock inversor o posición según los últimos datos del Registro de Inversiones Exteriores del Ministerio de Economía y Competitividad superiores a 3 millones de euros.

- Que se dé la pertenencia, en el caso de pequeñas y medianas empresas establecidas en España, a un sector considerado estratégico.

\footnotetext{
${ }^{25}$ Tal y como establece su propia exposición de motivos.

26 Visado y autorización de residencia para inversores, emprendedores, profesionales altamente cualificados, investigadores y para el supuesto de trabajadores que realicen movimientos intraempresariales dentro de la misma empresa o grupo de empresas.

${ }^{27}$ Si bien la LO 4/2000 en su artículo 38 ter, que remite a los artículos 85 a 94 del RD 557/2011, también prevé una autorización de residencia y trabajo para profesionales altamente cualificados, ésta no sería de aplicación para los deportistas de élite, ya que esta actividad no se encuentra prevista en la clasificación internacional de ocupaciones (CIUO) que es el creado por la Dirección General de Inmigración, que tras informar anualmente a la Comisión Laboral Tripartita de Inmigración sobre la evolución de las profesiones a las que resulte de aplicación el párrafo anterior.

${ }_{28}$ Contemplados en el artículo 71.a) de la LO 14/2013 según redacción dada tras la modificación por la Ley $25 / 2015$, de 28 de julio.
} 
En este caso, hay que tener en cuenta que pocos clubs van a tener el volumen requerido, aunque se encontrarían en este supuesto el Fútbol Club Barcelona y el Real Madrid $^{29}$ por ejemplo, o sino cabría la posibilidad de que el propio club, de manera previa a la solicitud de autorización de residencia para el deportista extranjero, solicitara a la Dirección General de Comercio un informe en el que la empresa fuera considerada como perteneciente a un sector estratégico, la cual cosa se puede solicitar a la Unidad de Grandes Empresas y Servicios Estratégicos (UGE) por un periodo de tres años ${ }^{30}$, o presentara un proyecto en el que éste fuera considerado de interés general.

Por último, la norma prevé la posibilidad de contratar a un profesional extranjero como altamente cualificado, en los casos en los que éste sea un graduado de prestigio, aunque en el caso de los deportistas de élite es de poca aplicación por no haber una titulación que le haga adecuado esa ocupación.

Este tipo de visados se solicitarán en las misiones diplomáticas correspondientes al país de origen del ciudadano extranjero, o a la del país en el que éste posea su residencia legal.

Una vez en España, el ciudadano extranjero podrá solicitar una autorización de residencia, ante la Unidad de Grandes Empresas de Madrid, autorización que tendrá carácter nacional y cuya duración será de dos años prorrogables (artículo 76 de la LO 14/2013).

Hay que precisar que para solicitar este tipo de autorización el ciudadano extranjero no puede encontrarse de manera irregular en España en el momento de la solicitud, por lo que el ciudadano extranjero podría realizar la solicitud de dicha autorización de residencia, estando en España con una autorización de estancia al encontrarse como turista. Es por este motivo que dicha solicitud se podrá iniciar con la tramitación del visado y posterior autorización de residencia y trabajo o directamente con la autorización de trabajo en España en el momento de que el ciudadano extranjero ya se encuentre regularmente en España.

\footnotetext{
${ }^{29}$ Ginesta Portet, X.: Football and the Global Entertainment Business. Clubs as Entertainment Multinational Corporations. Communication \& Society 24(1). 2011. Pág.141-166.

${ }^{30}$ Desde la modificación introducida por la Ley $25 / 2015$.
} 


\section{Especial referencia al cupo de deportistas no comunitarios permitido}

A la necesidad de los deportistas profesionales de solicitar la autorización de residencia y trabajo correspondiente, se le une la dificultad añadida de la imposición de las normas federativas a cerca del número máximo de deportistas profesionales no comunitarios que se permiten en los equipos, los cuales podrían ser cuestionados al establecer el artículo 23 de la LO 4/2000 la prohibición de discriminación directa o indirecta por la adopción de criterios que perjudiquen a los trabajadores por su condición de extranjeros o por pertenecer a una determinada raza, religión, etnia o nacionalidad $^{31}$.

Es por este motivo, que es importante es el hecho de las limitaciones que poseen los clubs deportivos o SAD (Sociedades Anónimas Deportivas), las cuales pueden contar con un máximo de tres jugadores extracomunitarios, entendiendo por tal a aquellos que no pertenezcan a un estado miembro de la UE o del EEE, tal y como establece el artículo 224.1.g) del Reglamento General de la Real Federación de Fútbol ${ }^{32}$ al hablar del cupo específico de jugadores extranjeros no comunitarios permitidos.

Es por este motivo, junto con el del arraigo con España tras años viviendo aquí, que muchos jugadores solicitan la nacionalidad española, ya que al club deportivo le interesa contar con un máximo número de deportistas españoles o nacionalizados. Al respecto encontramos jurisprudencia de la Unión Europea.

\section{Jurisprudencia de la Unión europea sobre cupos de deportistas extranjeros}

La Unión Europea no cuenta con competencia en materia deportiva. A través de la jurisprudencia iniciada por la sentencia del caso "Bosman" es cuando todo provoca un giro al pronunciarse el tribunal con respecto al derecho de los nacionales de otros estados miembros a participar en los encuentros deportivos.

\footnotetext{
${ }^{31}$ Bosch Capdevila, E y Franquet Sugrañes, M.T. (Coords): Dopaje, fraude y abuso en el deporte. Ed. Bosch.2007. Barcelona. Pág. 245.

Alonso Martínez, R: deportistas iberoamericanos y pasaporte comunitario. ¿Hacia la desaparición de las fronteras en el deporte profesional?. Lecturas EF y deporte, revista digital, http://www.efdeporte.com Fecha de consulta 25 de octubre de 2017)

32 Este Reglamento fue aprobado por la Comisión Delegada de la RFEF, y ratificado por la Comisión Directiva del Consejo Superior de Deportes en su sesión de 30 de junio de 2014.
} 
El caso "Bosman"33. El Tribunal de Justicia de la Unión Europea con sede en Luxemburgo dictó el 15 de diciembre de 1995 una sentencia ${ }^{34}$ en la cual declaraba ilegales las indemnizaciones por traspaso y los cupos de extranjeros de jugadores nacionales de estados miembros de la UE. La desaparición de los cupos de generó grandes efectos en el fútbol mundial. Si bien el Caso Bosman es el más conocido, éste ha tenido precursores, que han planteado al Tribunal de Justicia la controvertida cuestión de la libre circulación de los deportistas profesionales; en ese sentido encontramos los casos Walrave, referente al ciclismo (caso 36/74, Sentencia de 12 de diciembre de 1974) y Donà, relativo al fútbol (caso 13/76, Sentencia de 14 de julio de 1976) ${ }^{35}$.

Con posterioridad a la cuestión planteada por el caso Bosman, encontramos el acuerdo entre caballeros de $1991^{36}$, que anunció un cambio de real importancia como fue el reconocimiento del derecho de los clubes deportivos a contratar a cuantos jugadores extranjeros quisieran, sin limitación alguna.

Igualmente, se incluyó en dicho pacto, la posibilidad de que cada federación nacional limitara la participación de jugadores extranjeros en el mismo encuentro, así como la autorización a la UEFA a limitar el número de jugadores foráneos en las competiciones internacionales. En este sentido, el número máximo que se acordó para esas competiciones fue de tres jugadores extranjeros y dos asimilados (futbolistas con cinco años consecutivos de práctica en el país, tres de los cuales como jugador juvenil), regla denominada " $3+2$ "37 Esta opción UEFA es por la que optó la Real Federación Española de Fútbol para su competición nacional, y la que se aplica en la mayoría de países.

En segundo lugar, en relación con el caso anterior, referido a los cupos de deportistas extranjeros se encuentran la Sentencia Kolpak, C-438/00 dictada por el

\footnotetext{
${ }^{33}$ Sentencia de 15 de diciembre de 1995, el tribunal de justicia de la unión europea, sobre el denominado asunto "bosman" (c-415/93).

${ }^{34}$ Procedimiento iniciado en Bélgica y cuya primera sentencia del Tribunal de Primera Instancia de Lieja se dictó el 8 de agosto de 1990.

${ }^{35}$ Espartero Casado, J.: El avatar del tratamiento del deporte en el Derecho de la Unión Europea: por una especificidad deportiva compatible con los derechos y libertades fundamentales comunitarias. Anuario de Derecho Deportivo. Universidad Inca Garcilaso de la Vega/Asociación Española de Derecho Deportivo (AEDD), Lima (Perú), nº 1, 2010. Pág. 109-198.

${ }^{36}$ Gentlemen's agreement del año 1991, en vigor el 1 de julio de 1992. Revista General Informática Derecho número 622-623, 1996.

Conclusiones del Caso Bosman http://eur-lex.europa.eu/legalcontent/ES/ALL/?uri=CELEX\%3A61993CC0415 (fecha de consulta 8.11.2017).

http://www.iusport.es/opinion/crespo96.htm (fecha de consulta 8.11.2017).

${ }^{37}$ Crespo Pérez, J de D.: El caso Bosman: sus consecuencias. Revista General de Derecho (RGID) número 622-623. 1996.
} 
Tribunal de Justicia de la Unión Europea el 8 de mayo de 2003 en favor de Maroš Kolpak y la sentencia en la que se plantea el caso del deportista "Simutenkov", Sentencia del Tribunal de Justicia de la Unión Europea de 12 de abril de 2005, en el asunto C-265/03, en el que el Señor Igor Simutenkov de nacionalidad rusa, alegaba que debía ser considerado como "comunitario B" y por tanto no ser contabilizado dentro del cupo de tres jugadores extracomunitarios que podía tener el equipo, al existir un convenio entre Rusia y la UE, que establecía en su artículo 23, "la prohibición impuesta a cada Estado Miembro de tratar de manera discriminatoria, por razón de su nacionalidad, a los trabajadores rusos en relación con sus propios nacionales, por lo que respecta a sus condiciones de trabajo, retribución o despido"38.

España cuenta con acuerdos similares con otros países como Armenia, Azerbajyán, Georgia, Kazajistán, Kirguistán, Moldavia, Uzbekistán y Ucrania entre otros, por lo que otros deportistas extracomunitarios han conseguido posteriormente pronunciamientos a su favor por parte de los Tribunales españoles en su pretensión de ocupar plaza de extranjeros en igualdad de condiciones de los ciudadanos comunitarios, en virtud de Convenios Internacionales suscritos entre sus respectivos países y la UE; Malaja (polaco), Mills (Turco), Milic (esloveno), Timinskas y Stombergas (lituanos) y Karpin (estonio) y Kouba (checo) $)^{39}$ y jurisprudencia que ha dado la razón a los litigantes ${ }^{40}$, ya que la sentencia Kolpac no se aplica en España ${ }^{41}$.

\section{Nacionalidad española para deportistas extranjeros}

Muchos ciudadanos extranjeros optarán en el momento en el que lo puedan hacer, por solicitar la nacionalidad española con el fin de contar a partir de ese momento con una nacionalidad europea que les facilite en algunos casos la posibilidad de ser contratados en algún club deportivo.

Sucede en muchas disciplinas deportivas, que los deportistas extranjeros comparten su propia nacionalidad con la nacionalidad española que han obtenido, lo

\footnotetext{
${ }^{38}$ Braquehais Conesa, E.: los deportistas extra comunitarios en el ámbito de la Unión Europea. Revista Jurídica de la Comunidad de Madrid. 21 de mayo de 2005.

39 Caruncho, Tomé \& Judel, abogados y asesores fiscales. Boletín jurídico. http://caruncho-tomejudel.es/downloads/publicaciones/boletin-juridico/14 Deporextr.htm (fecha de consulta 8.11.2017).

${ }^{40}$ STSJ Cataluña de 19/03/2003 (JUR 130170), STSJ de Asturias de 12/01/2001 (AS 24), Juzgado de lo Social (JS) de Barcelona de 14/06/2000, en

Morant Vidal, J.: Las restricciones a la libre circulación de los deportistas por razón de nacionalidad. Revista de la Facultad de ciencias sociales y jurídicas de Elche. Núm. 1. Julio 2006, Págs. 164-179.

${ }^{41}$ Duran Ruiz, F.J.: De Bosman a Kolpak. Consecuencias de la aplicación del Derecho Comunitario en el deporte español. Rev. Derecho Deportivo número 5. Julio- diciembre 2003. Junta de Andalucía. Pág. 43.
} 
cual se hace muy patente por ejemplo en el mundo del fútbol. Como ejemplo de esto encontramos a Messi, Adriano y Alves del F.C. Barcelona, Marcelo del Real Madrid o Godin y Diego Costa en el Atlético de Madrid ${ }^{42}$.

A diferencia de lo que hemos visto anteriormente respecto a las solicitudes de autorizaciones de residencia y trabajo, donde los deportistas profesionales cuentan con un procedimiento específico para ellos, en el caso de las solicitudes de nacionalidad española deben seguir el mismo procedimiento.

Hay dos vías por las que estos ciudadanos extranjeros podrán pasar a ser ciudadanos españoles; solicitando la nacionalidad española por opción, lo cual realizan a instancia propia, o cuando les es concedida la nacionalidad española por carta de naturaleza, procedimiento que se realiza a instancia del propio Gobierno.

\subsection{Nacionalidad española por opción}

El código civil español establece en su artículo 20, qué ciudadanos tienen derecho a optar a la nacionalidad española, y salvo que se dé uno de estos supuestos ${ }^{43}$, el ciudadano extranjero que desee adquirir la nacionalidad deberá obtenerla por residencia legal, continuada e inmediatamente anterior a dicha solicitud.

Tal y como se prevé en el artículo 22 del Código Civil, el ciudadano extranjero que desee solicitar la nacionalidad española por residencia deberá haber residido en España diez años; bastarán cinco años para aquellos ciudadanos que hubieran adquirido la condición de refugiado y dos años cuando se trate de nacionales de origen de países iberoamericanos, Andorra, Filipinas, Guinea Ecuatorial o Portugal o de sefardíes ${ }^{44}$.

\footnotetext{
${ }^{42}$ Ortiz Cabanillas, J.M.: Fútbol y nacionalidad española por residencia. Iusport.com. http://iusport.com/not/2103/futbol-y-nacionalidad-espanola-por-residencia/ (fecha de consulta 20.10.2015).

${ }^{43}$ Se refiere este artículo a las personas que estén o hayan estado sujetas a la patria potestad de un español, a aquellas cuyo padre o madre hubiera sido originariamente español y nacido en España y a las que se hallen comprendidas en el segundo apartado de los artículos 17 y 19, referido a la posibilidad de optar por parte del interesado en el plazo de dos años desde que se determine la filiación siendo éste mayor de dieciocho años o desde que se haya producido la adopción.

${ }^{44}$ El supuesto de los sefardíes se ha desarrollado recientemente por la Ley 12/2015, de 24 de junio, en materia de concesión de la nacionalidad española a los sefardíes originarios de España (BOE núm. 151, de 25 de junio de 2015) y por la Instrucción de 29 de septiembre de 2015, de la Dirección General de los Registros y del Notariado, sobre la aplicación de la Ley 12/2015, de 24 de junio, en materia de concesión de la nacionalidad española a los sefardíes originarios de España (BOE núm. 234, de 30 de septiembre de 2015).
} 
Será suficiente la residencia de un año para el supuesto de que el ciudadano extranjero haya nacido en territorio español, en el caso de que éste no haya ejercitado oportunamente la facultad de optar, el que haya estado sujeto legalmente a la tutela, guarda o acogimiento de un ciudadano o institución españoles durante dos años consecutivos e incluso en el caso de que continuare en esta situación en el momento de la solicitud, el que al tiempo de la solicitud llevare un año casado con español o española y no estuviere separado legalmente o de hecho, el viudo o viuda de española o español, si en el momento de la muerte del cónyuge no existiera separación legal o de hecho y por último el nacido fuera de España de padre o madre, abuelo o abuela, que originariamente hubieran sido españoles.

\subsection{Nacionalidad española por carta de naturaleza}

Este supuesto se encuentra recogido en el artículo 21 del Código Civil que establece que la nacionalidad española se podrá obtener por carta de naturaleza, cuando así lo determine el poder ejecutivo de manera discrecional, mediante la publicación por Real Decreto de dicha concesión al considerarse que concurren circunstancias excepcionales para ello ${ }^{45}$.

Si bien no hay un criterio uniforme conocido, ya que se desconocen los criterios que utiliza el Consejo de Ministros para otorgar la nacionalidad por carta de naturaleza, lo cierto es que nos encontramos muchos ejemplos de concesión de nacionalidad española por esta vía concedida a favor de deportistas de élite, aunque también encontramos casos, en los que sin razón aparente, este procedimiento se ha denegado o ha tardado mucho.

Por un lado encontramos casos en los cuales no se ha concedido, como es el caso de Mauri Castillo (atletismo) y otros en que el ciudadano extranjero ha debido acudir al procedimiento por residencia o casos en los cuales el procedimiento se ha dilatado mucho, como es el caso de Adel Mechaal (atletismo) que debió esperar cuatro años para obtener la nacionalidad española o el caso de Joan Lino (salto de longitud) que debió

\footnotetext{
45 Junto con España, encontramos también la posibilidad de conceder la nacionalidad por causas excepcionales en Grecia, Italia, Luxemburgo y Bélgica.
} 
esperar ocho. Otros atletas, se manifiestan en contra de la masiva nacionalización de atletas extranjeros ${ }^{46}$.

Entre los últimos en ser concedidos en el año 2015, año en el que se ha batido un récord al nacionalizar a diez deportistas encontramos a:

RD 112/2015, por el se concede la nacionalidad española por carta de naturaleza a Don Viktor Lazarenko (gimnasta) ${ }^{47}$.

RD 113/2015, por el se concede la nacionalidad española por carta de naturaleza a Doña Helena Cecilia Bonilla (gimnasta) ${ }^{48}$.

RD 114/2015, por el se concede la nacionalidad española por carta de naturaleza a Don Gonzalo Óscar Echenique (waterpolista) ${ }^{49}$.

RD 115/2015, por el se concede la nacionalidad española por carta de naturaleza a Annebel Van Der Knijff (piragüista) ${ }^{50}$.

RD 117/2015, por el se concede la nacionalidad española por carta de naturaleza a Doña Yevheniha Chystyakova (deportista de orientación) ${ }^{51}$.

RD 118/2015, por el se concede la nacionalidad española por carta de naturaleza a Doña Darly Zoqbi De Paula (balonmano) ${ }^{52}$.

RD 191/2015, por el se concede la nacionalidad española por carta de naturaleza a Don Yidiel Contreras (atleta) ${ }^{53}$.

Real Decreto 464/2015, por el que se concede la nacionalidad española por carta de naturaleza a Don Lliass Fifa (atleta) ${ }^{54}$.

RD 724/2015, por el se concede la nacionalidad española por carta de naturaleza a Don Thierno Boubocar Diallo (gimnasta) ${ }^{55}$.

\footnotetext{
46 http://www.elmundo.es/deportes/2015/07/31/55ba8f40ca4741f41c8b4625.html (fecha de consulta 25.10.2015).

${ }^{47}$ BOE núm. 57, de 7 de marzo de 2015.

${ }^{48}$ BOE núm. 57, de 7 de marzo de 2015.

${ }^{49}$ BOE núm. 57, de 7 de marzo de 2015.

${ }^{50}$ BOE núm. 57, de 7 de marzo de 2015.

${ }^{51}$ BOE núm. 57, de 7 de marzo de 2015.

${ }^{52}$ BOE núm. 57, de 7 de marzo de 2015.

${ }^{53}$ BOE núm. 77, de 31 de marzo de 2015.

${ }^{54}$ BOE núm. 150 de 24 de junio de 2015.
} 
RD $725 / 2015$, por el se concede la nacionalidad española por carta de naturaleza a Don Orlando Orteaga Alejo (atleta) ${ }^{56}$.

\section{CONCLUSIONES}

La principal conclusión que se puede extraer del presente estudio es la gran importancia que tienen y que se les da al mundo de los deportes en España. Aunque se ha hecho gran publicidad de las nuevas autorizaciones de residencia de la Ley de Emprendedores para atraer a la inmigración de calidad, esto ya existía con anterioridad, al igual que en países como EEUU, respecto al mundo de los deportes y concretamente referido a determinados deportistas de élite, a los cuales se les reservan diversas prerrogativas para que puedan regularizar su situación de residencia en España.

La segunda conclusión es remarcar dicha importancia del mundo del deporte, para que el poder ejecutivo, tras propuesta de las Federaciones, incluso llegue más lejos haciendo uso de su potestad, concediendo una nacionalidad española por carta de naturaleza a determinados deportistas de élite.

En tercer lugar vemos como el concepto jurídico indeterminado para conceder la nacionalidad española a deportistas de élite es totalmente discrecional, considerándolo existente en unos casos y en otros no, tal y como ha quedado de manifiesto en la explicación.

\footnotetext{
${ }^{55}$ BOE núm. 191, de 11 de agosto de 2015.

${ }^{56}$ BOE núm. 191, de 11 de agosto de 2015.
} 


\section{BIBLIOGRAFÍA}

- Alonso Martínez, R: deportistas iberoamericanos y pasaporte comunitario. ¿Hacia la desaparición de las fronteras en el deporte profesional?. Lecturas EF y deporte, revista digital, http://www.efdeporte.com Fecha de consulta 25 de octubre de 2017)

- Bosch Capdevila, E y Franquet Sugrañes, M.T. (Coords): Dopaje, fraude y abuso en el deporte. Ed. Bosch.2007. Barcelona. Pág. 235.

- Braquehais Conesa, E.: los deportistas extra comunitarios en el ámbito de la Unión Europea. Revista Jurídica de la Comunidad de Madrid. 21 de mayo de 2005.

- Caruncho, Tomé \& Judel, abogados y asesores fiscales. Boletín jurídico. http://caruncho-tome-judel.es/downloads/publicaciones/boletinjuridico/14 Deporextr.htm (fecha de consulta 8.11.2017).

- Crespo Pérez, J de D.: El caso Brosman: sus consecuencias. Revista General de Derecho (RGID) número 622-623. 1996

- Duran Ruiz, F.J.: De Bosman a Kolpak. Consecuencias de la aplicación del Derecho Comunitario en el deporte español. Rev. Derecho Deportivo número 5. Juliodiciembre 2003. Junta de Andalucía.

- Espartero Casado, J.: El avatar del tratamiento del deporte en el Derecho de la Unión Europea: por una especificidad deportiva compatible con los derechos y libertades fundamentales comunitarias. Anuario de Derecho Deportivo. Universidad Inca Garcilaso de la Vega/Asociación Española de Derecho Deportivo (AEDD), Lima (Perú), nº1, 2010. Pág. 109-198.

- Ginesta Portet, X. (2011). Football and the Global Entertainment Business. Clubs as Entertainment Multinational Corporations. Communication \& Society 24(1). Pág.141-166.

- Morant Vidal, J.: Las restricciones a la libre circulación de los deportistas por razón de nacionalidad. Revista de la Facultad de ciencias sociales y jurídicas de Elche. Núm. 1. Julio 2006.

- Ortiz Cabanillas, J.M.: Fútbol y nacionalidad española por residencia. Iusport.com. http://iusport.com/not/2103/futbol-y-nacionalidad-espanola-por-residencia/ (fecha de consulta 20.10.2015).

http://www.elmundo.es/deportes/2015/07/31/55ba8f40ca4741f41c8b4625.html (fecha de consulta 25.10.2015).

- Conclusiones del Caso Bosman http://eur-lex.europa.eu/legalcontent/ES/ALL/?uri=CELEX\%3A61993CC0415 (fecha de consulta 8.11.2017).

- Acuerdo de 21 de junio de 1999, entre la Comunidad se les aplica el Régimen Comunitario. DOUE núm. 114, de 30 de abril de 2002.

- Ley Orgánica 4/2000 (Ley Orgánica 4/2000, de 11 de enero, sobre Derechos y Libertades de los Extranjeros en España y su Integración Social. BOE núm. 10, de 12 de enero de 2000)

- Ley Orgánica 6/2006, de 19 de julio Estatuto de Autonomía de Cataluña (BOE núm. 172 de 20 de Julio de 2006) 
- Ley 14/2013, de 27 de septiembre, de apoyo a los emprendedores y su internacionalización (BOE núm. 233, de 28 de septiembre de 2013).

- Ley $12 / 2015$, de 24 de junio, en materia de concesión de la nacionalidad española a los sefardíes originarios de España (BOE núm. 151, de 25 de junio de 2015)

- Ley 25/2015, de 28 de julio, de mecanismo de segunda oportunidad, reducción de la carga financiera y otras medidas de orden social (BOE núm. 180, de 29 de julio de 2015).

- Real Decreto 1006/1985, por el que se regula la relación laboral especial de los deportistas profesionales (BOE núm. 153, de 27 de junio de 1985).

- Real Decreto Legislativo 1/1995, de 24 de marzo, por el que se aprueba el texto refundido de la Ley del Estatuto de los Trabajadores (BOE núm. 75, de 29 de marzo de 1995).

- Real Decreto 240/2007, de 16 de febrero, sobre entrada, libre circulación y residencia en España de ciudadanos de los Estados Miembros de la Unión Europea y de otros Estados parte en el Acuerdo sobre el Espacio Económico Europeo. (BOE núm. 51, de 28 de febrero de 2007).

- Real Decreto 1463/2009, de 18 de septiembre, sobre traspaso de funciones y servicios a la Generalitat de Cataluña en materia de inmigración: autorizaciones iniciales de trabajo por cuenta propia o ajena de los extranjeros cuya relación laboral se desarrolle en Cataluña. (BOE núm. 229, de 22 de septiembre de 2009).

- Real Decreto 557/2011, de 20 de abril por el que se aprueba el Reglamento de la Ley Orgánica 4/2000, sobre derechos y libertades de los extranjeros en España y su integración social, tras su reforma por Ley Orgánica 2/2009. BOE núm. 103, de 30 de abril de 2011).

- Real Decreto-ley 16/2012, de 20 de abril, de medidas urgentes para garantizar la sostenibilidad del Sistema Nacional de Salud y mejorar la calidad y seguridad de sus prestaciones. (BOE núm. 98, de 24 de abril de 2012).

- Reglamento General de la Rea Federación de Fútbol aprobado por la Comisión Delegada de la RFEF, y ratificado por la Comisión Directiva del Consejo Superior de Deportes en su sesión de 30 de junio de 2014.

- RESOLUCIÓN de 19 de julio de 2005, de la Secretaría General para la Administración Pública, por la que se dispone la publicación del Acuerdo del Consejo de Ministros de 15 de julio de 2005, para la implantación de una Red de Oficinas Integradas de Atención al Ciudadano en colaboración con las Comunidades Autónomas y las Entidades que integran la Administración Local (BOE núm. 184, de 3 de agosto de 2005).

- Resolución de 12 de agosto de 2005, de la Secretaría de Estado de inmigración y Emigración, por la que se dispone la del Acuerdo de Consejo de Ministros, de 15 de julio de 2005, por el que se aprueban las instrucciones por las que se determina el procedimiento para autorizar la residencia y el desarrollo de actividades laborales deportivas profesionales por extranjeros (BOE núm. 200, de 22 de agosto de 2005).

- INSTRUCCIÓN DGI/SGRJ/02/2009, sobre el acuerdo de Consejo de Ministros, de 15 de julio de 2006, por el que se aprueban las instrucciones por las que se determina el procedimiento para autorizar la residencia y el desarrollo de 
actividades laborales deportivas

profesionales

por extranjeros. http://extranjeros.empleo.gob.es/es/normativa/nacional/general extranjeria/instrucci ones_sgie/documentos/2009/INSTRUCCION_DGI-SGRJ-02-2009.pdf (fecha de consulta 22 de octubre de 2015).

- Instrucción de 29 de septiembre de 2015, de la Dirección General de los Registros y del Notariado, sobre la aplicación de la Ley 12/2015, de 24 de junio, en materia de concesión de la nacionalidad española a los sefardíes originarios de España (BOE núm. 234, de 30 de septiembre de 2015).

- Gentlemen's agreement del año 1991, en vigor el 1 de julio de 1992.

- Acuerdo que tiene por objeto establecer los criterios conforme a los cuales, los extranjeros de cualquier nacionalidad que se encuentren de manera irregular en territorio nacional y manifiesten su interés de residir en el mismo, puedan promover la obtención de su documentación migratoria en la calidad de inmigrante con las características de profesional, cargo de confianza, científico, técnico, familiares, artistas o deportistas o bien, en la característica de asimilado en los casos que de manera excepcional se establecen en el presente. Diario Oficial de la Federación (primera sección) de martes de 11 de noviembre de 2008. Mexico. 